\title{
IMPROVED ESTIMATES OF MEAN SEA LEVEL CHANGES IN THE SOUTH-EASTERN NORTH SEA SINCE 1843
}

\author{
Jürgen Jensen ${ }^{1}$, Thomas Wahl ${ }^{1}$ and Torsten Frank ${ }^{1}$ \\ Keywords: German Bight, regional sea level changes, tide gauge data, vertical land movements
}

\begin{abstract}
This contribution focuses on presenting the results from analysing mean sea level changes in the German Bight, the south-eastern part of the North Sea. Data sets from 13 tide gauges covering the entire German North Sea coastline and the period from 1843 to 2008 have been used to estimate high quality mean sea level time series. The overall results from nonlinear smoothing and linear trend estimations for different time spans are presented. Time series from single tide gauges are analysed as well as different 'virtual station' time series. An accelerated sea level rise in the German Bight is detected for a period at the end of the 19th century and for another one covering the last decades. In addition, different patterns of sea level change are found in the German Bight compared to global patterns, highlighting the urgent need to derive reliable regional sea level projections to be considered in coastal planning strategies.
\end{abstract}

\section{INTRODUCTION}

Changing sea levels are one of the major concerns we have to deal with in times of a warming climate. Many authors recently studied observed global sea level changes based on tide gauge or altimetry data (e.g. Cazenave et al. 2008; Church and White 2006; Church et al. 2008; Domingues et al. 2008; Woodworth et al. 2009; Wöppelmann et al. 2009) and future projections have been assessed through numerical model studies (summarised in Meehl et al. 2007) or from semi-empirical models (Grinsted et al. 2009; Jevrejeva et al. 2010; Rahmstorf 2007; Vermeer and Rahmstorf 2009). The results of these studies clearly point to the existence of regional variability in the patterns of sea level change, e.g. due to an uneven distribution of meltwater from ice sheets and glaciers or a non-uniform thermal expansion. As Miller and Douglas (2007) and Woodworth et al. (2010) reported, changes in ocean circulation may also contribute to different behaviours of sea level changes at different sites. If different regional patterns and trends have been observed in the past, there is no reason why it should not be the same in the future. Currently, global sea level projections from the IPCC's Fourth Assessment Report (Meehl et al. 2007) are used for most coastal planning purposes, knowing that there may be significant regional differences. To overcome this inadequacy, reliable regional sea level projections are urgently needed. Thus, regional sea level studies have become all the more important in recent years. The observed changes in mean sea level (MSL) in the German Bight from 1843 to 2008 are presented in this paper and among others may contribute to the verification of regional models used for the estimation of future scenarios. The data availability for German North Sea gauges is very good in a worldwide comparison (Wahl et al. 2008). However, the high resolution time series, which are available for a large number of tide gauges for at least the last decade, have not been used for detailed analyses to date.

The structure of the paper is as follows: In Section 2, the considered data sets and the investigation area are presented. The methodology used to generate and analyse the high quality MSL time series is discussed. For more detailed information about the applied methods see Wahl et al. (2010). The results from analysing time series derived from single tide gauges by applying non-linear smoothing techniques and estimating linear trends for common time periods are presented in Section 3.1. Section 3.2 contains the results from analysing a virtual station time series for the entire German Bight. Afterwards, the results for the German Bight are compared to a global virtual station and to another one for the North-East-Atlantic region (Section 3.3). The paper concludes with a summary of the key findings and an outline for further research activities.

\footnotetext{
${ }^{1}$ Research Institute for Water and Environment, University of Siegen, Paul-Bonatz-Str. 9-11, 57076 Siegen, Germany
} 


\section{DATA AND METHODS}

Figure 1 shows the investigation area in the south-eastern North Sea and the locations of the tide gauges considered for the present study. Altogether 13 tide gauges were selected, as they are almost equally distributed along the coastline and provide high quality sea level measurements over a time period of at least 50 years. The latter has been identified as a sufficient length for long-term trend analyses (Douglas 1991; Pugh 2004), although the underlying variability has still to be taken into account. The effect of the length of the time series on the resulting long-term trend and the related standard error, respectively, has been outlined by Haigh et al. (2009). Originally 18 tide gauges were selected for the study, but some were not considered due to impacts from inland drainage (tide gauges of Schlüttsiel and Bensersiel), from barrages (tide gauge of Tönning), from significant coastal engineering measures (tide gauge of Büsum) or due to suspicious data (tide gauge of Borkum).

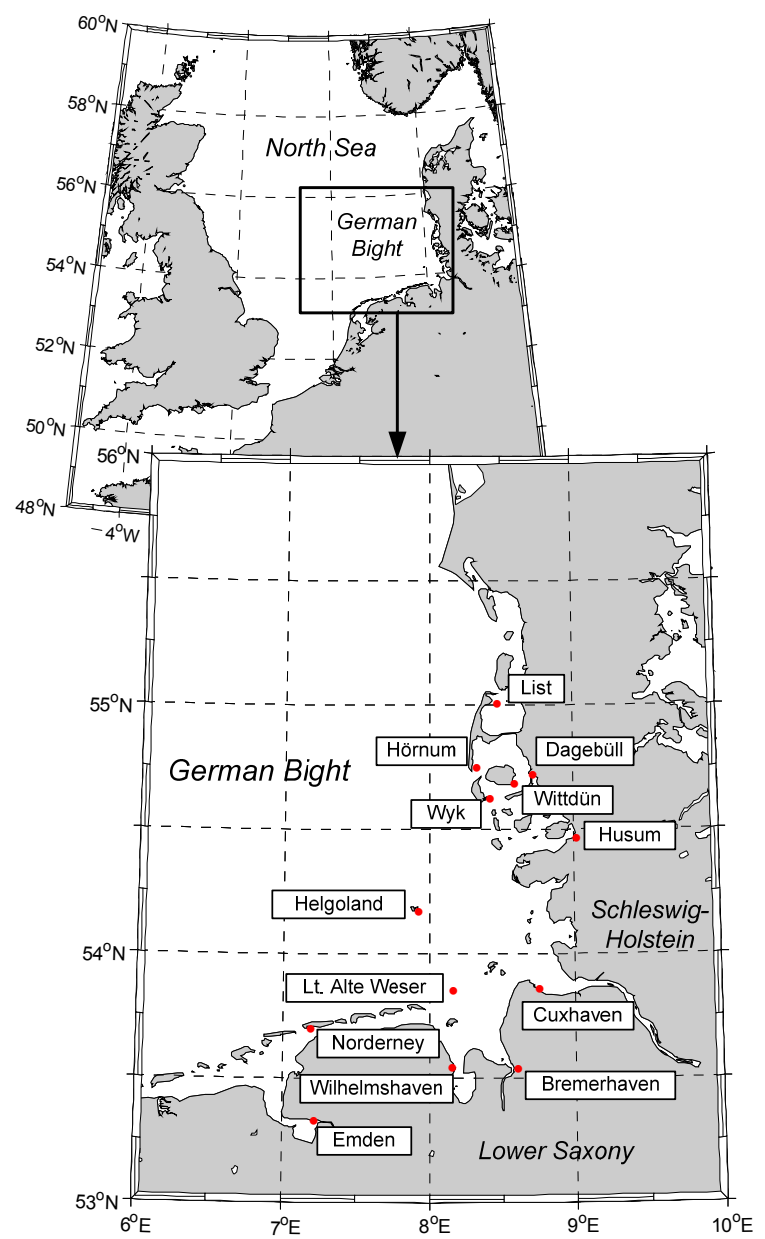

Figure 1. Investigation area and locations of the considered tide gauges along the German North Sea coastline.

Figure 2 shows an overview of the available data sets and distinguishes between data sets providing semidiurnal high and low waters (averaging leads to mean tide level (MTL)) and data sets providing high resolution data (i.e. at least hourly values; averaging leads to mean sea level). High resolution data sets are available since the late 1990s for most of the considered tide gauges. The tide gauges of Heligoland, Cuxhaven and Wilhelmshaven provide longer high resolution data sets as a result of former digitization exercises. To partially resolve the shortcoming of missing high resolution data from the past for tide gauges covering the north-eastern part of the German Bight, some data from the tide gauges of Hörnum $(1951,1965,1976,1987)$ and Wyk $(1951,1952)$ have recently been digitised by the Agency of Roads, Bridges and Water in Hamburg and the Ministry of Agriculture, Environment and Rural Areas in Schleswig-Holstein, respectively. All considered data sets were 
checked for conspicuous data and corrected for local datum shifts, as reported in IKÜS (2008). No inverse barometer correction was applied.

To combine the MSL time series resulting from the high resolution data and the MTL time series resulting from the low resolution data, a monthly $k$-factor time series $k(t)$ is estimated. The dimensionless $\mathrm{k}$-factor is a reference value for the difference between MSL and MTL and calculated for the time period providing high resolution data using Eq. (1) (Lassen, 1989):

$$
k(t)=\frac{(M H W(t)-M S L(t))}{M T R(t)}
$$

where $\operatorname{MHW}(t)$ is the monthly mean high water, $\operatorname{MSL}(t)$ is the monthly mean sea level and $\operatorname{MTR}(t)$ is the monthly mean tidal range. For the German North Sea coastline, k-factors are found to vary between about 0.43 and 0.49 . A k-factor of 0.5 means that the tide curve has a perfect sinusoidal form and that MSL equals MTL.

Before combining MSL and MTL time series, it has to be tested whether the k-factor is a stationary parameter for the investigated gauge station or whether it shows non-stationary behaviour. Therefore, two tests on stationarity are applied to the monthly k-factor time series. The first one is a sliding-window test with a window length of one year to account for possible seasonality (Mudersbach and Jensen, 2008; van Gelder, 2008). The second test is a two dimensional non-parametric Kolmogorov-Smirnov test (Chen and Rao, 2002; Mudersbach and Jensen, 2008). If the k-factor is found to be stationary, a monthly MSL time series can be easily estimated with Eq. (2):

$$
\operatorname{MSL}(t)=\operatorname{MTR}(t) \cdot(0.5-k)+\operatorname{MTL}(t)
$$

where $\operatorname{MSL}(t)$ is the monthly mean sea level, MTR(t) is the monthly mean tidal range, $\mathrm{k}$ is the mean $\mathrm{k}$ factor estimated from the time period providing high resolution data and MTL $(\mathrm{t})$ is the monthly mean tide level. If the k-factor shows non-stationary behaviour, a first or higher order polynomial fit has to be applied and extrapolated before correcting MTL values or different (stationary) k-factors have to be used for different time periods. Equation (3) considers a time dependent k-factor:

$$
\operatorname{MSL}(t)=\operatorname{MTR}(t) \cdot(0.5-k(t))+\operatorname{MTL}(t)
$$

where the variables are the same as in Eq. (2) and $\mathrm{k}(\mathrm{t})$ is the time dependent $\mathrm{k}$-factor.

The k-factors estimated for the considered tide gauges can be seen from Fig. 2. Non stationary behaviour has been detected for example for the tide gauge of Wilhelmshaven, where a k-factor of 0.4597 is used to transfer MTL data to MSL data for the time period of 1936 to 1950 and a k-factor of 0.4670 for the time period of 1975 to 1999 . High resolution data are available for the other time periods and MSL can be calculated directly from the data. As can be seen in Fig. 2, the Cuxhaven tide gauge provides the longest record (starting in 1843), followed by Norderney (starting in 1901) and Lt. Alte Weser (starting in 1903). Most tide gauges provide data from 1936/1937 onwards. The tide gauge of Emden shows the lowest mean k-factor of 0.4286, which means a strong deformation of the tide curve due to shallow water effects and, considering a mean tidal range of $323 \mathrm{~cm}$, a difference between MTL and MSL of about 23 centimetres. The highest k-factor of 0.4874 is derived for the tide gauge of Norderney and equals a difference between MTL and MSL of only 3 centimetres (considering a mean tidal range of $244 \mathrm{~cm}$ ).

Once a consistent MSL time series has been generated, different methods can be used to analyse the long-term and recent linear and non-linear behaviour. Parametric approaches provide the advantage of allowing extrapolation into the future, whereas data adaptive non-linear methods are valuable to detect inflection points and periods of remarkably high or low rates of SLR. 


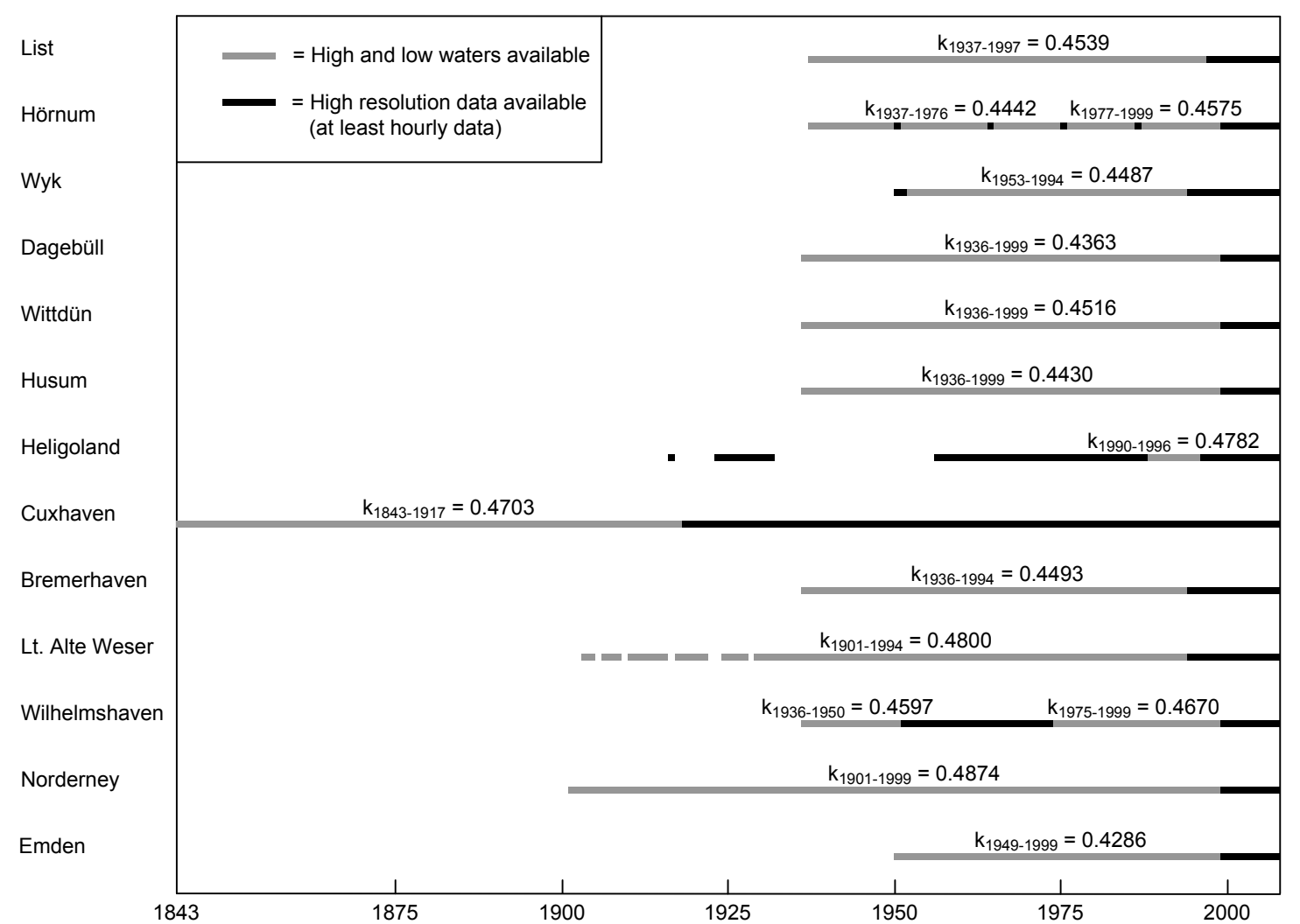

Figure 2. Available data sets and the calculated k-factors for different time periods, which have been used to transfer the MTL data, derived from tidal high and low waters, to MSL data.

The method used to analyse the mean sea level time series is described in detail in Wahl et al. (2010) and only briefly discussed here. For non-linear smoothing, singular system analysis (SSA) with an embedding dimension of 15 years is applied in combination with Monte-Carlo autoregressive padding (MCAP), an advanced approach to assess the uncertainties due to the padding of time series. Applying SSA in combination with MCAP involves: (1) the detrending of the time series; (2) the estimation of a large number of surrogates using an AR1 model; (3) the padding of the detrended original time series using the ends of the surrogates (which are two times the chosen embedding dimension longer than the original time series); (4) re-including the long-term trend; (5) identifying the EOFs providing trend information, (6) reconstruction considering the previously identified "trend EOFs"; and finally, (7) identifying the reconstruction providing the smallest mean squared error (MSE) against the observations. As an improvement to the approach described in Wahl et al. (2010), the parametric function (first order, second order or exponential) providing the best fit is used for detrending the original time series, not necessarily a linear function. This reduces the required number of Monte-Carlo simulations to achieve stable results for the smoothing near the boundaries. The rates of SLR are estimated as the first deviation of the SSA reconstruction providing the best fit (e.g. Fig. 3). Linear trends from single time series are estimated for common time spans to ensure comparability and 1- $\sigma$ standard errors (equal to $68 \%$ confidence levels) are quoted (Tab. 1). A virtual station time series, which is assumed to be representative for the entire German Bight is determined by averaging the observed rates of SLR per year (first deviation), from the time series of the considered tide gauges. The resulting time series is integrated backwards and analysed in detail as stated above (e.g. Fig. 5). In the next step, the virtual station for the entire German Bight is related to a global and a trans-regional sea level reconstruction by comparing the observed rates of SLR and estimating correlation coefficients for running 20-year periods (Fig. 6). 


\section{RESULTS}

\subsection{Mean sea level changes along the German North Sea coastline}

Fig. 3 shows the results from non-linear smoothing by SSA for the considered tide gauges. An embedding dimension of 15 years is applied in combination with 10,000 MCAP simulations to find the optimal data adaptive smooth for the particular time series.

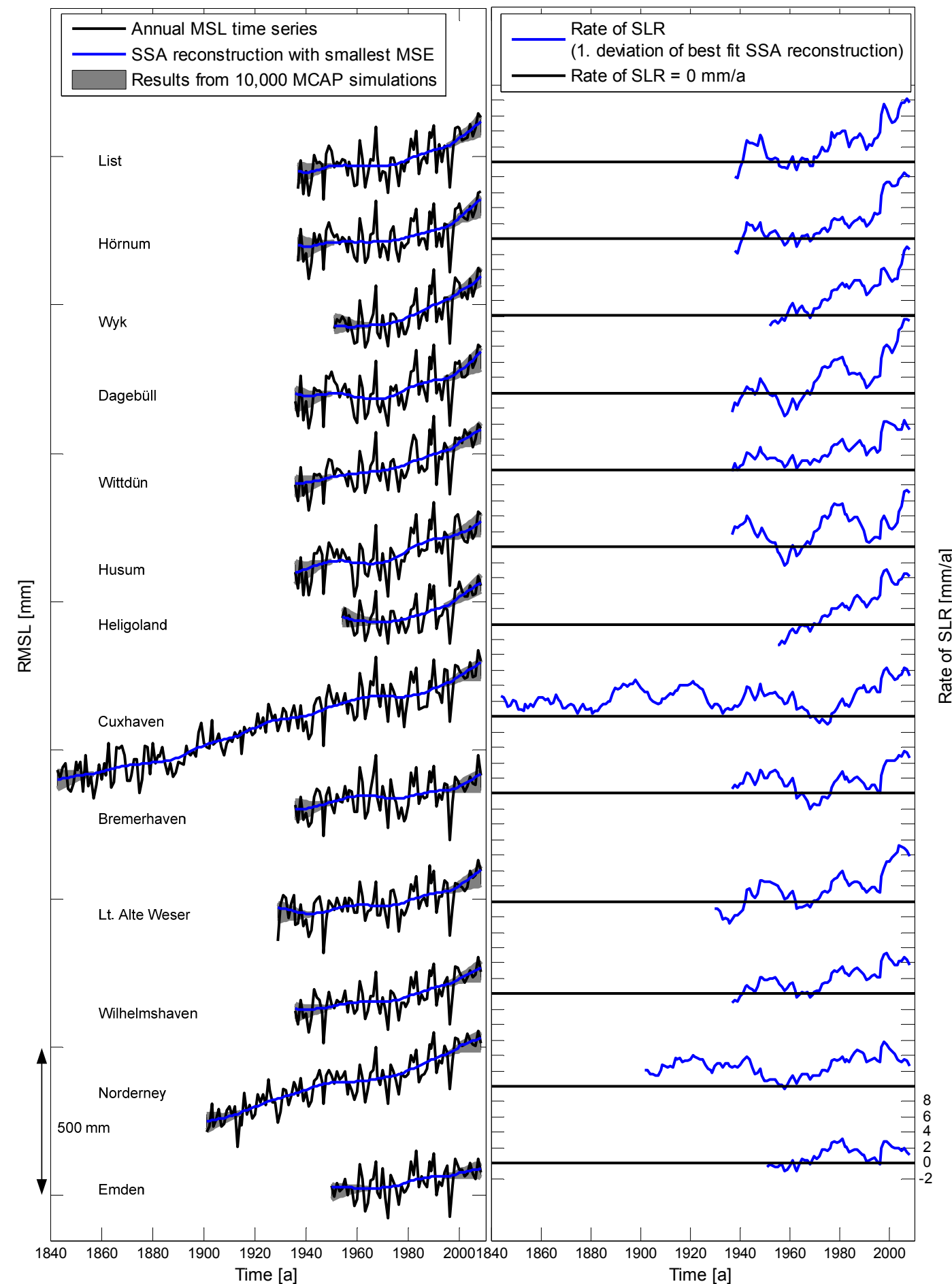

Figure 3. Mean sea level time series for the considered tide gauges and results from non-linear smoothing applying SSA with an embedding dimension of 15 years in combination with 10,000 MCAP simulations (left) and rates of SLR estimated as the first deviation from the SSA reconstruction providing the best fit (right); all time series have been plotted with arbitrary offsets for presenting purposes. 
The underlying annual MSL time series are in good agreement, showing noticeable high or low values for the same years, which indicates high data quality. Most of the smoothed time series point to an accelerated SLR over the last few decades, with its starting point around 1970. For most of the shorter records, the estimated recent rates of SLR are the highest ones observed, whereas longer records (Cuxhaven and Norderney) show more similar rates in the past.

These findings are confirmed by calculating linear trends for different common time periods, as shown in Tab. 1. All stated errors are 1- $\sigma$ standard errors (equivalent to $68 \%$ confidence levels). Remarkably higher trends are estimated for the time period from 1971 to 2008, compared to the periods from 1951 to 2008 and 1937 to 2008. The long records show slightly higher rates again, when longer time periods (1901 to 2008 or 1843 to 2008) are considered. To single out the period starting in 1951, for which data are available for all considered tide gauges and being long enough for reliable long-term trend analyses, the trends vary between $1.01 \mathrm{~mm} / \mathrm{a}$ for the tide gauge of Bremerhaven and $2.81 \mathrm{~mm} / \mathrm{a}$ for the tide gauge of Norderney. Standard errors are in the order of $0.4 \mathrm{~mm} / \mathrm{a}$. The tide gauge of Norderney is strongly influenced by the local datum corrections (IKÜS 2008). The estimated long-term trend (1843 to 2008) for the Cuxhaven station is $2.28 \mathrm{~mm} / \mathrm{a}$. Trends found for the period starting in 1971, which has been identified as the staring point of the recent SLR acceleration, are mostly $>3.5 \mathrm{~mm} / \mathrm{a}$. Standard errors for this short time period are in the order of $0.75 \mathrm{~mm} / \mathrm{a}$.

Table 1. Linear trends with 1- $\sigma$ standard errors and correlation coefficients for common time periods for single time series and virtual station time series.

\begin{tabular}{|c|c|c|c|c|c|}
\hline \multirow{2}{*}{ Tide gauge } & \multicolumn{5}{|c|}{$\begin{array}{l}\text { Linear trends of RMSL for different time spans } \pm 1-\sigma \text { standard errors [mm/a] } \\
\text { (correlation with 'virtual station' - German Bight) }\end{array}$} \\
\hline & $1843-2008$ & $1901-2008$ & $1937-2008$ & $1951-2008$ & $1971-2008$ \\
\hline List & - & - & $1.99 \pm 0.31(0.98)$ & $2.42 \pm 0.43(0.98)$ & $4.21 \pm 0.75(0.98)$ \\
\hline Hörnum & - & - & $1.75 \pm 0.31(0.98)$ & $2.06 \pm 0.43(0.98)$ & $3.73 \pm 0.79(0.98)$ \\
\hline Wyk & - & - & - & $2.76 \pm 0.47(0.98)$ & $4.55 \pm 0.78(0.97)$ \\
\hline Dagebüll & - & - & $1.72 \pm 0.35(0.95)$ & $2.20 \pm 0.47(0.96)$ & $3.74 \pm 0.89(0.97)$ \\
\hline Wittdün & - & - & $2.35 \pm 0.30(0.97)$ & $2.59 \pm 0.42(0.97)$ & $3.88 \pm 0.83(0.97)$ \\
\hline Husum & - & - & $2.16 \pm 0.34(0.96)$ & $2.48 \pm 0.47(0.96)$ & $3.63 \pm 0.89(0.97)$ \\
\hline Heligoland & & - & - & $2.09 \pm 0.42^{*}(0.96)$ & $3.54 \pm 0.69(0.96)$ \\
\hline Cuxhaven & $2.28 \pm 0.08(0.99)$ & $2.15 \pm 0.16(0.96)$ & $2.10 \pm 0.32(0.95)$ & $1.96 \pm 0.43(0.94)$ & $3.62 \pm 0.80(0.94)$ \\
\hline Bremerhaven & - & - & $1.19 \pm 0.32(0.92)$ & $1.01 \pm 0.45(0.90)$ & $2.45 \pm 0.83(0.94)$ \\
\hline LT Alte Weser & - & $1.91 \pm 0.19^{*}(0.88)$ & $1.73 \pm 0.28(0.95)$ & $1.70 \pm 0.38(0.95)$ & $3.10 \pm 0.77(0.96)$ \\
\hline Wilhelmshaven & - & - & $1.85 \pm 0.26(0.98)$ & $1.99 \pm 0.36(0.99)$ & $3.41 \pm 0.70(0.99)$ \\
\hline Norderney & - & $2.37 \pm 0.13(0.95)$ & $2.36 \pm 0.26(0.96)$ & $2.81 \pm 0.35(0.95)$ & $4.24 \pm 0.64(0.96)$ \\
\hline Emden & - & - & - & $1.34 \pm 0.37(0.94)$ & $2.06 \pm 0.72(0.94)$ \\
\hline $\begin{array}{l}\text { 'virtual Station' } \\
\text { (German Bight) }\end{array}$ & $2.01 \pm 0.08$ & $1.68 \pm 0.14$ & $1.96 \pm 0.26$ & $2.14 \pm 0.39$ & $3.60 \pm 0.74$ \\
\hline
\end{tabular}

* Some years of the considered time period are missing, but at least $93 \%$ are available (see also Fig. 2)

\subsection{Results from analysing a virtual station time series for the entire German Bight}

In this section, the results from estimating and analysing a virtual station time series for the entire German Bight are presented. As stated above, the virtual station is determined by first differentiating the single time series, before averaging the resulting rates of sea level changes between adjacent years. In the next step, the resulting time series is integrated backwards to achieve the virtual station time series for the entire German Bight. As can be seen from Fig. 2 only the Cuxhaven tide gauge provides data for the period before 1900 (and two to four gauges from then on until the mid 1930s), which increases the uncertainties for this time period(s). Nonetheless, leaving such historical information unconsidered would be irresponsible.

Fig. 4 shows the results from analysing the virtual station time series in the same way as stated above. Obviously, an acceleration of SLR took place at the end of the 19th century, followed by a deceleration. The SLR started to accelerate again around the 1970s with a post 1990 intensification, leading to high recent rates in the order of 4 to $5 \mathrm{~mm} / \mathrm{a}$. These findings are similar to those reported in 
Wahl et al. (2010), based on the results from analysing only two tide gauges (Cuxhaven and Heligoland). Linear trends of the virtual station for the entire German Bight are presented in Tab. 1 and are in the order of $2 \mathrm{~mm} / \mathrm{a}$ for most of the considered time spans. The trend estimated for the period from 1971 to 2008 is $3.60 \pm 0.74 \mathrm{~mm} / \mathrm{a}$, which is in the order of the global trend of $3.36 \pm 0.41 \mathrm{~mm} / \mathrm{a}$ found by Beckley et al. (2007) from altimetry data for a much shorter time period (from 1993 onwards). Considering the reduced period from 1993 to 2008, a trend of $7.26 \mathrm{~mm} / \mathrm{a}$ is estimated for the German Bight, which is more than twice the trend found from global altimetry data. However, the vertical land movements are included for the German Bight (in the order of $0.5 \mathrm{~mm} / \mathrm{a}$, see chapter 3.4) and the standard error increases to $2.70 \mathrm{~mm} / \mathrm{a}$, due to the high variability and the short time period that is considered.

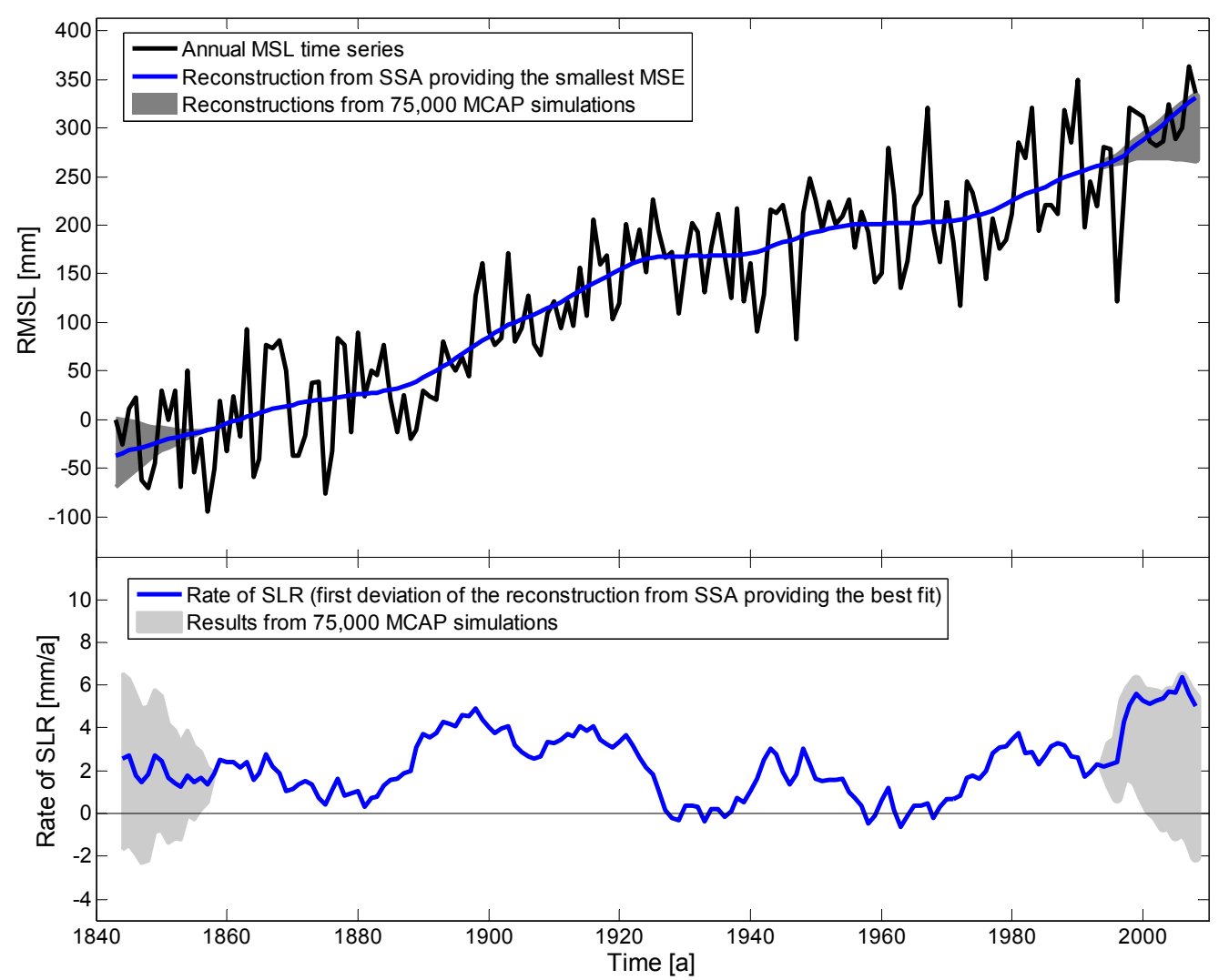

Figure 4. Virtual station time series for the entire German Bight and results from non-linear smoothing applying SSA in combination with MCAP.

To sum up the findings from analysing the virtual station it can be stated that the observed high recent rates and the related SLR acceleration are not unusual considering the last 166 years of observations from tide gauges in the German Bight. Nevertheless, the results also highlight the necessity for further research in the field of regional sea level analyses by considering additional climate related parameters. In addition, updating the presented results at regular intervals will be necessary to examine whether another deceleration will take place in the near future or whether the starting point in the 1970s denotes the beginning of an anthropogenic influenced SLR acceleration.

\subsection{Mean sea level changes in the German Bight compared to global and trans-regional changes}

To compare the mean sea level time series for the German Bight with larger scale sea level reconstructions, Fig. 5 shows the results from estimating running 20-year correlation coefficients from the virtual station of the German Bight and a global reconstruction and a North-East-Atlantic reconstruction, respectively (Jevrejeva et al. 2006). The 95\%-significance levels (from t-test statistics) are also displayed, pointing out that most of the estimated correlation coefficients from the time series of the German Bight and the global reconstruction are insignificant $(66 \%$ percent of the estimated 
coefficients for 20 -year periods). In contrast, $83 \%$ of the 20 -year correlation coefficients estimated for the reconstruction of the German Bight and the reconstruction of the North-East-Atlantic are found to be significant.

Nonetheless, the results illustrate the necessity for further analyses to compare the reconstruction of the German Bight with some global, trans-regional or other regional sea level reconstructions in detail. More complex methods should be applied to achieve more reliable results and time series of additional relevant parameters (e.g. atmospheric pressure, North-Atlantic-Oscillation) should be considered, as they allow further insights into the underlying processes.

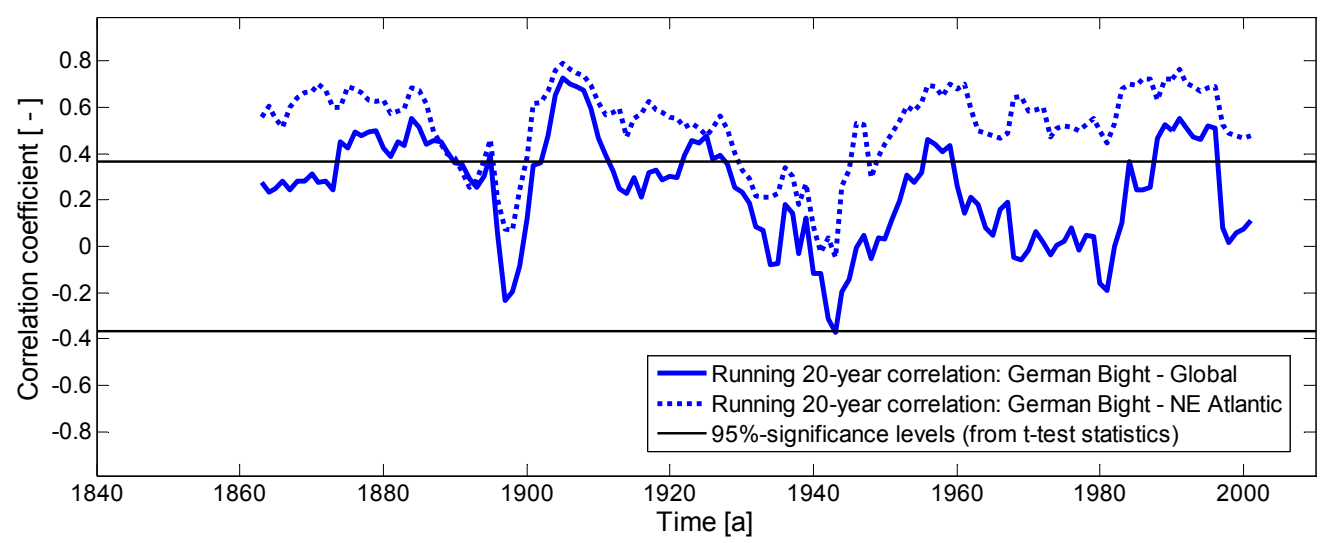

Figure 5. 20-year running correlation coefficients between the virtual station of the entire German Bight and a global virtual station and the virtual station of the entire German Bight and a virtual station for the NorthEast-Atlantic (each correlation coefficient is displayed for the last year of the considered 20-year period).

Many different sea level rise scenarios (most of them for the year 2100) have recently been published by different authors (a summary of selected scenarios can be found in Mudersbach and Jensen 2010), whereas some of them are based on numerical model simulations and some on semiempirical models. From an extensive literature study, Gönnert et al. (2009) derive a sea level rise scenario for the area of the city of Hamburg for the year 2100 of 40 to $80 \mathrm{~cm}$. In comparison, the observed increase in the German Bight from 1843 to 2008 was estimated to be $34 \mathrm{~cm} \mathrm{(14} \mathrm{cm} \mathrm{from}$ 1937 to 2008 and $11 \mathrm{~cm}$ from 1993 to 2008), whereas vertical land movements are included and may be responsible for one third or even the half of the observed changes.

\section{CONCLUSIONS AND OUTLINE}

In this paper observed MSL changes in the German Bight over the last 166 years are presented. Analyses have been conducted for relative mean sea level time series from 13 tide gauges covering the entire German North Sea coastline and for a virtual station comprising the time series from single gauges. It was found that the considered MSL time series are of very good quality showing high correlation with the estimated virtual station for the entire German Bight. Non-linear smoothing techniques are applied to identify the underlying long-term variability, which includes the identification of periods with considerably high or low rates of SLR.

To sum up the key findings, it was found that an acceleration of SLR occurred at the end of the 19 th century followed by a deceleration. Another acceleration with its starting point in the 1970s and intensification from the 1990s on cannot be denoted as unusual or possibly attributed to anthropogenic impacts considering the last 166 years of observations. Nevertheless, the reported findings highlight the necessity for further studies and a regular update of the presented results.

The regional patterns of sea level change in the German Bight are identified by analysing a virtual station comprising all considered tide gauges. The comparison with a global sea level reconstruction and a virtual station for the North-East-Atlantic reveals different patterns of sea level changes, whereas better agreement is found for the German Bight and the North-East-Atlantic reconstruction. Further studies including the application of more complex methods to compare time series on different time scales are necessary and to achieve a better insight into the underlying processes the consideration of additional climate related parameters seems to be useful.

To conclude, the presented results indicate the importance of regional sea level studies based on long and high quality sea level observations and it is recommended to put some efforts in further 
digitisation exercises and data archaeology. That will provide important information to better understand the underlying processes, which is essential to improve the accuracy of regional sea level rise scenarios to be considered in coastal management strategies.

\section{ACKNOWLEDGEMENTS}

We thank Svetlana Jevrejeva (Proudman Oceanographic Laboratory) for providing us the reconstructed mean sea level time series of the North-East-Atlantic and we highly acknowledge the German Coastal Engineering Research Council (KFKI) and the German Federal Ministry of Education and Research (BMBF) for funding the research project "AMSeL - Mean Sea Level and Tidal Analysis at the German North Sea Coastline".

\section{REFERENCES}

Augath W (1993) Stand und Weiterentwicklung der Höhenüberwachung der niedersächsischen Nordseeküste. Nachrichten der Niedersächsischen Vermessungs- und Katasterverwaltung 43: 7892.

Beckley BD, Lemoine FG, Luthcke SB, Ray RD, Zelensky NP (2007) A reassessment of global and regional mean sea level trends from TOPEX and Jason-1 altimetry based on revised reference frame and orbits. Geophys. Res. Lett., 34, L14608. doi:10.1029/2007GL030002, 2007.

Cazenave A, Dominh K, Guinehut S, Berthier E, Llovel W, Ramillien G, Ablain M, Larnicol G (2009) Sea level budget over 2003-2008: A reevaluation from GRACE space gravimetry, satellite altimetry and Argo. Global and Planetary Change 65:83-88.

Chen HL, Rao AR (2002) Testing Hydrologic Time Series for Stationarity, J. Hydrologic Eng., 7( 2), 129-136, doi: 10.1061/(ASCE)1084-0699(2002)7:2(129).

Church JA, White NJ (2006) A 20th century acceleration in global sea-level rise. Geophys. Res. Lett., 33, L01602. doi:10.1029/2005GL024826.

Church JA, White NJ, Aarup T, Wilson SW, Woodworth PL, Domingues CM, Hunter JR, Lambeck K (2008) Understanding global sea levels: past, present and future. Sustain Sci 3(1):9-22. doi: 10.1007/s11625-008-0042-4.

Domingues CM, Church JA, White NJ, Gleckler PJ, Wijffels SE, Barker PM, Dunn JR (2008) Improved estimates of upper-ocean warming and multi-decadal sea-level rise. Nature 453:10901093. doi:10.1038/nature07080.

Douglas BC (1991) Global Sea Level Rise, J. Geophys. Res. 96(C4):6981-6992. doi:10.1029/91JC00064.

Haigh ID, Nicholls RJ, Wells NC (2009) Mean sea-level trends around the English Channel over the 20th century and their wider context. Continental Shelf Research 29:2083-2098.

IKÜS (2008) Aufbau eines integrierten Höhenüberwachungssystems in Küstenregionen durch Kombination höhenrelevanter Sensorik (final report). Online available from: http://tudresden.de/die_tu_dresden/fakultaeten/fakultaet_forst_geo_und_hydrowissenschaften/fachrichtun g_geowissenschaften/gi/gg/veroeffentlichungen/BMBF03KIS055-58.pdf.

Jensen J, Mügge H-E, Schönfeld W (1990) Development of Water Level Changes in the German Bight - An Analysis Based on Single Value Time Series. Proc. 22nd ICCE, Delft, Netherlands.

Jevrejeva S, Grinsted A, Moore JC, Holgate S (2006) Nonlinear trends and multiyear cycles in sea level records. J. Geophys. Res., 111, C09012. doi:10.1029/2005JC003229.

Jevrejeva S, Moore JC, Grinsted A. (2010) How will sea level respond to changes in natural and anthropogenic forcings by 2100?. Geophys. Res. Lett., 37, L07703. doi:10.1029/2010GL042947.

Lassen H (1989) Örtliche und zeitliche Variationen des Meeresspiegels in der südöstlichen Nordsee, Die Küste, 50, 65-96.

Meehl GA, Stocker TF, Collins WD, Friedlingstein P, Gaye AT, Gregory JM, Kitoh A, Knutti R, Murphy JM, Noda A, Raper SCB, Watterson IG, Weaver AJ, Zhao Z-C (2007) Global Climate Projections. In: Climate Change 2007: The Physical Science Basis. Contribution of Working Group I to the Fourth Assessment Report of the Intergovernmental Panel on Climate Change [Solomon S, Qin D, Manning M, Chen Z, Marquis M, Averyt KB, Tignor M, Miller HL (eds.)]. Cambridge University Press, Cambridge, United Kingdom and New York, NY, USA.

Miller L, Douglas BC (2007) Gyre-scale atmospheric pressure variations and their relation to 19th and 20th century sea level rise. Geophys. Res. Lett., 34, L16602. doi:10.1029/2007GL030862. 
Mudersbach C, Jensen J (2008) Non-stationarities in time series and its integration in extreme value statistics for risk management issues. Proc. of the 31st Int. Conf. on Coastal Engineering (ICCE), Hamburg, Germany.

Mudersbach C, Jensen J (2010) An advanced statistical extreme value model for evaluating storm surge

heights considering systematic records and climate scenarios, Proc. 32nd ICCE, Shanghai, China (in prep.).

Peltier WR (2004) Global Glacial Isostasy and the Surface of the Ice-Age Earth: The ICE-5G(VM2) model and GRACE. Ann. Rev. Earth. Planet. Sci. 32:111-149. doi: 10.1146/annurev.earth.32.082503.144359.

Pugh D (2004) Changing Sea Levels: Effects of Tides, Weather and Climate. Cambridge Univ. Press, New York.

Rahmstorf S (2007) A Semi-Empirical Approach to Projecting Future Sea-Level Rise, Science, 315, 5810, 368-370. doi: 10.1126/science.1135456.

Van Gelder PHAJM., Mai CV, Wang W, Shams G, Rajabalinejad M, Burgmeijer M (2008) Data management of extreme marine and coastal hydro-meteorological events, J. Hyd. Res., 46( 2), 191210.

Vermeer M, Rahmstorf S (2009) Global sea level linked to global temperature. doi: 10.1073/pnas.0907765106.

Wahl T, Jensen J, Frank T (2008) Changing Sea Level and Tidal Dynamics at the German North Sea Coastline. Proc. of the Coastal Cities Summit 2008 - Values and Vulnerabilities, St. Petersburg, Florida, USA .

Wahl T, Jensen J, Frank T (2010) On analysing sea level rise in the German Bight since 1844. Nat. Hazards Earth Syst. Sci. 10:171-179. doi:10.5194/nhess-10-171-2010.

Woodworth PL, Teferle FN, Bingley RM, Shennan I, Williams SDP. (2009) Trends in UK mean sea level revisited. Geophys. J. Int. 176(22):19-30. doi: 10.1111/j.1365-246X.2008.03942.x.

Woodworth PL, Pouvreau N, Wöppelmann G (2010) The gyre-scale circulation of the North Atlantic and sea level at Brest. Ocean Sci. 6:185-190. doi:10.5194/os-6-185-2010.

Wöppelmann G, Miguez BM, Bouin M-N, Altamimi Z (2007) Geocentric sea-level trend estimates from GPS analyses at relevant tide gauges world-wide. Global and Planetary Change 57:369-406.

Wöppelmann G, Letetrel C, Santamaria A, Bouin M-N, Collilieux X, Altamimi Z, Williams SDP, Miguez BM (2009) Rates of sea-level change over the past century in a geocentric reference frame. Geophys. Res. Lett., 36, L12607. doi:10.1029/2009GL038720. 